\title{
Low Carbon Economy Development and Carbon Emission Reduction in Western China
}

\author{
Xiangsheng Dou \\ School of Economics and Management, Southwest Jiaotong University, Chengdu, China \\ Email: douxiangsheng@tsinghua.org.cn
}

How to cite this paper: Dou, X.S. (2017) Low Carbon Economy Development and Carbon Emission Reduction in Western China. Theoretical Economics Letters, 7, 1081-1101.

https://doi.org/10.4236/tel.2017.75073

Received: May 7, 2017

Accepted: June 30, 2017

Published: July 3, 2017

Copyright (c) 2017 by author and Scientific Research Publishing Inc. This work is licensed under the Creative Commons Attribution International License (CC BY 4.0).

http://creativecommons.org/licenses/by/4.0/

(c) (i) Open Access

\begin{abstract}
Western China is not only an important ecological conservation area, but also has rich natural resources and environmental conditions. Therefore, the western China must vigorously develop green low carbon economy to realize the win-win of natural ecological environment protection and socio-economic development. At present, the western China has not only great potential in technology progress, industrial upgrading and energy saving and emission reduction, but also has good endowment conditions and comparative advantages in the development of agricultural carbon sequestration, eco-tourism and clean energy development. Therefore, the western region in China should make full use of these advantages to promote low carbon economy development. At the present stage, the western China should actively promote industrial upgrading and structural optimization, comprehensively implement natural ecological protection engineering, reasonably develop and utilize mineral resources, fully utilize renewable clean energy resources, promote eco-tourism, give priority to organic ecological agriculture, and accelerate urbanization and urban ecology-oriented development.
\end{abstract}

\section{Keywords}

Western China, Low Carbon Economy Development, Ecological Environment Protection, Socio-Economic Development

\section{Introduction}

The western region in China covers 12 provinces, autonomous regions and municipalities with a total area of 16.85 square kilometers, accounting for $71.4 \%$ of China's land area. Water resources and mineral resources in the western region are rich, and the proportion of natural forest and grassland is larger than others, accounting for $66.2 \%$ and $89.4 \%$ of China's total natural forest and grassland, respectively. Especially, the western region in China has variety of wildlife 
resources, so the western region in China's ecosystem is in a key position [1].

As an important growth point of future China's economic development, economic development mode formed from western development project will have a comprehensive impact on China's economic structure [2]. Because the western ecological environment system is not only important but also relatively fragile, how to scientifically develop and implement comprehensive ecological environmental protection is an important problem to be solved in the social and economic development of the western region. In this case, vigorously to develop low carbon economy has very important practical significance. Especially, in order to avoid the recurrence of environmental protection mode of "first development and then governance" in the east, it is of great significance to ensure socioeconomy and ecological sustainable development.

Because of the vast territory of China, not only social and economic development in China is uneven, but also the ecological environment is very different, which determines that regional low carbon economy development is vital. The initial development of western region mainly depends on agricultural and mineral resources development, and is still in the primary stage of industrialization development with the obvious heavy chemical industrial characteristics of power, iron and steel, chemical industry, which has hindered industrial structure upgrading in the western region. In addition, the remote geographical location of western region also largely blocked the capital, technology and other high-tech elements of inland areas to the western region, which determines industrial structure in western region is difficult to change completely in a long time [3].

With increasingly industrial and capital intensity in the east area, the largescale transfer of industries in the east area to the western region is inevitable. However, due to the large differences in the level and structure of economic development between the western and the eastern regions, it is impossible to achieve regional economic revitalization by large-scale acceptance of the "three high" industrial transfer in the eastern region. On the contrary, this development mode may have a negative impact on socio-economy and ecological environment in the western region.

Some scholars believe that, because of vast territory, a sparse population, and abundant resources in the western region, the western region can attract capital from the east by regional environmental policy differences in currently social and economic backward stage. In fact, although regional environmental policy differences will have different effects on investment, consumption and environment, whether the implementation is of the same environmental policy or different environmental policies is extremely negative for the western region. If the western region implements more permissive environmental standards than the eastern region, it will attract more capital and investment, but at the same time the total pollution will also surge [4]. Obviously, trying to revitalize the western economy through industrial transfer from the eastern region is not consistent with the law of social and environmental development in the western region.

Compared with capital intensive and technologically developed eastern coastal 
areas, the western region is lack of both funds and technology. Although total carbon emissions in the western region are relatively low compared with the eastern region, carbon emissions per GDP in the western region are $39.7 \%$ higher than that of the eastern region [2]. Therefore, carbon emission intensity in the western region is higher due to backward technology. From the perspective of total factor productivity and technology progress index, the eastern region is more prominent, but the western region is relatively low, which is the root cause of high carbon emissions per capita [5].

There is a close link between environmental pollution and per capita income. In theory, in the early period of underdevelopment economy, environment protection is deteriorating with the growth of per capita income. Once income reaches a certain level, environment will gradually improve with the increase of income, which is the famous "environmental Kuznets curve" [6]. However, as it has not reached the Kuznets inflection point due to weak industrial base in the western region, so there is a positive correlation trend of income and carbon emissions in the early industrialization, and it is closely related to technology backwardness and capital deficiency in the western region [7] [8]. Because of this, some people think that it can regulate the income level of the western region through price and tax policy to alleviate carbon emissions caused by social and economic development in the western region [9]. However, due to low income per capita in the western region, income reduction policy will lead to greater marginal efficiency loss, which will have a greater negative impact on the quality of life and economic development of people in the underdeveloped western region. Of course, as the western region has rich natural gas, coal and oil resources, so these resources become the powerful support of resource-based economy development in the western region. However, because of the characteristics of high pollution and low production utilization of resource industry itself, if not scientifically to develop and utilize resources, or to make disruptive development and utilization of resources, it will cause serious damage to the environment. On the other hand, rich natural and ecological resources in the western region, especially huge potential clean energy resources, have created conditions for the development of clean energy and other low carbon industries. Hydropower potential in the western region accounts for $82.3 \%$ of the nation, and light energy and geothermal resources in the northwest and southwest area are extremely rich, providing great natural advantages for the development and utilization of clean energy [3] [10].

Compared to other parts of the country, although the western region has great differences in energy consumption and economic and social development from the eastern region, it still has some advantages in resources and environmental protection, especially in forest carbon sequestration [11]. Because the western region has rich natural vegetation resources and mineral resources, it has incomparable comparative advantage in the development of ecological agriculture, ecological tourism, renewable energy industry, forest carbon sequestration industry, and the deep processing and utilization of mineral resources relatively to 
other regions [1] [12]. Therefore, as a new growth point of China's future economy, the western region should make full use of its natural resources and environmental endowment conditions, and completely transform extensive economic growth mode and promote low carbon economy development.

\section{Method and Model}

\subsection{Scenario and Issues}

To develop low carbon economy has become an established strategy in China. China has also incorporated low carbon economy development into the medium-and long-term planning of national economic and social development, and set up a binding index of $40 \%$ to $50 \%$ cut by 2020 compared to 2005 [13]. Shaanxi, Gansu, Ningxia, Sichuan, Chongqing, Guizhou, Yunnan, Qinghai, Tibet, Xinjiang, Inner Mongolia and Guangxi, as the planning area of "western development", bear the twofold task of regional economic growth and energy saving and environmental protection. Therefore, vigorously to develop low carbon economy, and fully to achieve the dual objectives of economic development and environmental protection, have become an inevitable choice for the western development in the future.

As the western region is currently in the stage of heavy industrialization development, resource-oriented industry and heavy industry occupy the dominant position of economic development. However, resource utilization and production efficiency are low, and the carbon emissions of output per unit is larger. In fact, economic growth in the western region is based on high pollution and high energy consumption. The industrial added value of western China accounted for $14.8 \%$ of the country in 2007 , but the proportion of industrial waste water, solid waste and waste gas produced from western China accounted for $22.5 \%, 56.1 \%$ and $26.9 \%$ of the country respectively. At the same time, the intensity of carbon emissions in the western region is far higher than that in the middle and eastern regions, especially in some energy production provinces [14].

Under the pressure of the dual objectives of rapid economic growth and environmental protection, the economy of the western region has still relatively rapid development in the decade. The gross domestic product in the western region reached 8082.51 billion Yuan RMB in 2010, increasing about 3.85 times compared with 2000. At the same time, although total carbon emissions are still in a continuous growth stage, both technical efficiency and energy utilization efficiency continue to improve with rapid economic development. Especially after 2000 , due to the promotion of the western development project, the total emissions (TE) have increased sharply with the rapid growth of GDP. It is worth affirming that the carbon emissions of unit GDP in the western region (AE) keep downward trend.

The reason for above problem is that, on the one hand, the proportion of resource-based and heavy industrialization industries in national economy is rising due to the promotion of the western development projects, resulting in high emission intensity of unit GDP. On the other hand, the empirical study shows 
that total factor technology progress index including low carbon technology in the western region is lower than traditional technical progress index [5]. In the dual role of marginal technology efficiency diminishing and technology gap accumulation, the emission cuts of unit output value have slowed down.

\subsection{Measure Method and Carbon Emission Model}

In order to further analyze emission trend in the western region, the following formula is used to calculate total emissions in the western region:

$$
\text { Total emissions }(\mathrm{TE})=\text { unit output value emissions }(\mathrm{AE}) \times \mathrm{GDP}
$$

The reasons for selecting output value per unit (AE) and regional gross domestic product (GDP) as forecast variables are that, firstly because the unit output value can be introduced as a replacement variable of emission cut technology, avoiding the deficiency of technical coefficient measurement. Secondly, this equation can clarify the relationship between total emissions (TE) and economic gross value (GDP) and technical level.

The derivation of time $t$ may be obtained from Equation (1):

$$
\frac{\partial \mathrm{TE}}{\partial t}=\frac{\partial \mathrm{AE}}{\partial t} \times \mathrm{GDP}(t)+\frac{\partial \mathrm{GDP}}{\partial t} \times \mathrm{AE}(t)
$$

where $\frac{\partial \mathrm{TE}}{\partial t}$ represents the change rate of total emissions in the western region. $\frac{\partial \mathrm{AE}}{\partial t}$ the change rate of emissions per unit output. $\frac{\partial \mathrm{GDP}}{\partial t}$ the growth rate of gross domestic product in the western region.

Using the data of GDP and emissions per unit GDP in the western China from 1988 to 2009, two functions may be obtained:

$$
\begin{gathered}
\mathrm{AE}=\underset{(11.57)}{1.43}+\underset{(11.54)}{4.92 / t} \\
F=133.1 R^{2}=0.89 \\
\ln \mathrm{GDP}=\underset{(12.25 .2)}{8.25}+\underset{(27.1)}{0.14 t} \\
F=733.6, R^{2}=0.98
\end{gathered}
$$

Equation (3) and Equation (4) indicate that there is a specific trend change relationship between emissions per unit GDP, regional GDP and time t.

Further, the following equations may be obtained:

$$
\begin{gathered}
\frac{\partial \mathrm{AE}}{\partial t}=-4.92 / t^{2} \\
\frac{\partial \mathrm{GDP}}{\partial t}=0.14 \mathrm{e}^{8.25+0.14 t} \\
\frac{\partial \mathrm{TE}}{\partial t}=\mathrm{e}^{8.25+0.14 t}\left(-4.92 / t^{2}+0.69 / t-0.2\right)
\end{gathered}
$$

Equation (7) shows that, if $\frac{\partial \mathrm{TE}}{\partial t}>0$, then total emissions are in a continuing growth state given other conditions. Because the constant is always greater than 0 , only change in $\left(-4.92 / t^{2}+0.69 / t-0.2\right)$ need to be considered. It is found 
that $t=-11.6$ and $t=3.5$ are two root of the parabola. Therefore, when $t \geq 4$, the value of variable $\frac{\partial T E}{\partial t}$ is always greater than 0 . This means that, according to current growth mode, except for the negative growth of carbon emissions from 1988 to 1991 for the western region, the total amount of carbon emissions in the western region will continue to grow.

On the premise of total carbon emission control, we find that continuous positive growth may not only fail to complete emission control task, but also total pollution will make a continuous rise. This will result in more serious environmental pollution. In the wave of low carbon economy development, the western region should seize such opportunity and use its endowment and advantages to improve its competitiveness in the "new economic development mode", and to build a diversified economic development system and enhance comprehensive competitive advantage.

In addition, the western region, as the birthplace and ecological barrier of the Yellow River and the Yangtze River, has a far-reaching environmental impact on overall environment, and is the key area of environmental protection for China, because of its vast coverage area, complex topography, resource enrichment and ecological fragility. Therefore, the western region of China must seek scientific development way, and pay great attention to the win-win of economy development and environment protection, and vigorously develop low carbon economy, in order to fundamentally change unsustainable economic development mode. This has important strategic significance to the western region as well as to the whole country.

\subsection{Emission Reduction Model}

Unlike the eastern region, social and economic development for the western region is relatively backward. Therefore, how to quickly promote socio-economic development and the comprehensive protection of ecological environment are two important tasks of low carbon economy development in the western region. In the previous analysis, we have found the following important relationship between total economic volume, emissions per unit output and total emissions:

$$
\frac{\partial \mathrm{TE}}{\partial t}=\frac{\partial \mathrm{AE}}{\partial t} \times \mathrm{GDP}(t)+\frac{\partial \mathrm{GDP}}{\partial t} \times \mathrm{AE}(t)
$$

Therefore, under the premise of ensuring rapid economic development, in order to curb the rapid growth of greenhouse gas emissions, the greater the absolute value of $\partial \mathrm{AE} / \partial t$ will be the better, revealing that the carbon emissions of unit output will have a great decline, while the improvement of technology and energy use efficiency is the key. Secondly, introduction to emission reduction technology will not only have a great impact on the value of $\partial \mathrm{AE} / \partial t$, but also cut the carbon emissions $\operatorname{AE}(t)$ of unit energy significantly, which both reduce the growth rate of greenhouse gas. Finally, under the premise of not affecting GDP growth, the transformation of economic growth structure and growth mode can improve the quality of economic development and reduce the proportion 
of high carbon energy in economic growth, and can also reduce the emissions of unit capacity and pollution growth rate.

In the actual situation of the western region, current work for the western region should focus on actively promoting industrial upgrading and structural optimization, comprehensive implementation of natural ecological protection engineering, rational development and utilization of mineral resources, and full utilization of renewable clean energy resources, vigorously promoting the development of eco-tourism, giving priority to organic ecological agriculture, and accelerating urbanization and urban ecology-oriented development. Therefore, the dual goals and tasks of socio-economic development and environmental protection can be achieved through these channels.

\section{Results and Evaluation}

\subsection{Technology Progress, Industrial Upgrading and Emission Reduction}

Technology is the decisive factor of more than all other driving factors in solving greenhouse gas emission reduction. For the western region in the development stage of heavy industry, the low level development and high energy consumption problems of industries generally exist. Energy efficiency in the western China is lower than national average 10\%. More importantly, technology and independent innovation ability in the western region are long-term lower than other regions, and technology "lock-in effect" is extremely remarkable, so the introduction and development of low carbon technology is particularly urgent.

However, because the western region in the process of attracting investment and industrial transfer is difficult to attract advanced industries due to the constraints of development environment, the existing level of emission reduction technology is limited and the great gap exists compared with the eastern region [15]. Especially the extreme lack of regional innovation talent in industrial system will weaken the development of pillar industries in the western region, which brings a great obstacle to low carbon development [14].

Although the backwardness of technology in the western area has brought obstacles to real economic development, it also provides a great opportunity for future low carbon economy development in the western region. On the one hand, as long as the state and western regions implement effective policies in the $\mathrm{R} \& \mathrm{D}$, introduction and promotion of low carbon technologies, then it will be conducive to promote the significant improvement of resources and energy efficiency in the western region. On the other hand, lower energy efficiency and high carbon intensity in the western region caused by the severe shortage of capital and technology, reveal the huge potential of emission reduction in the western region, which will become the dominant factor to attract advanced technology at home and abroad. In particular, the western region may make full use of the CDM mechanism of international environmental cooperation, and cooperate with enterprises in developed countries or developed areas, so that the contradiction of the lack of funds and technology can be effectively overcome. This 
will inject new elements and vitality into enterprise and industrial development in the western region.

Industry is the largest energy consumption sector. Since 1990, the proportion of industrial energy consumption to total energy consumption has remained about $70 \%$. The leading industries in the western region are mainly electricity, chemistry and iron and steel. Because of high energy consumption and high pollution, industrial carbon emissions in the western region have increased from 55.6 million tons in 1995 to 137.8 million tons in 2009, increasing $148 \%$. In particular, energy consumption in western areas is dominated by coal, and the coal, as primary energy consumption, is higher than the national average of $25 \%$, reaching more than $90 \%$ [16]. As shown in Table 1 that, coal in energy consumption structure has been hovering over $70 \%$ in the "eleventh five-year" period. This also shows that coal-dominated energy structure is an important obstacle to low carbon economy development in the western region. Therefore, to optimize energy structure and improve the proportion of oil and gas in total energy consumption, is one of the important ways to reduce carbon emission intensity. At the same time, it also shows that the western region has great potential in industrial energy saving.

Although industry is the leading source of carbon emissions in the western region, it can be found from the difference of carbon emissions in different industries in the central and western regions that, there is a certain gap between other sectors and industrial sector. The carbon emissions of construction industry in the western region were less and showed a gentle trend during "the tenth five-year plan" and "the eleventh five-year plan". As shown in Table 2 that, carbon emissions in construction industry have grown from 0.008 ten thousands of tons in 2000 to 0.017 ten thousands of tons in 2009, increasing 0.009 ten thousands of tons only in the decade. However, because energy consumption in construction industry includes heating, lighting, power, air conditioning and other energy consumption, the energy saving and emission reduction of construction sectors is very necessary in the process of urbanization. As the northwest areas have a long cold winter, it has to pay enough attention to the development and promotion of composite wall, insulation glass and other thermal materials to reduce the demand for energy consumption and pressure on carbon emissions [14].

Table 1. Energy consumption in the western China

\begin{tabular}{cccc}
\hline Year & $\begin{array}{c}\text { Total energy consumption } \\
\text { in western China } \\
\text { (million of tons standard coal) }\end{array}$ & $\begin{array}{c}\text { Total coal consumption } \\
\text { in western China } \\
\text { (million of tons standard coal) }\end{array}$ & $\begin{array}{c}\text { The proportion of coal } \\
\text { consumption to total } \\
\text { energy consumption }(\%)\end{array}$ \\
\hline 2005 & 626.10 & 448.32 & 71.6 \\
2006 & 694.10 & 551.02 & 79.4 \\
2007 & 765.00 & 561.76 & 73.4 \\
2008 & 821.49 & 610.73 & 74.3 \\
2009 & 881.57 & 674.70 & 76.5 \\
\hline
\end{tabular}

Source: China energy statistic yearbook 2010. 
Table 2. Industrial carbon emissions in the western region.

\begin{tabular}{lccccc}
\hline Year & $\begin{array}{c}\text { Agriculture, } \\
\text { Animal Husbandry } \\
\text { and Fishery } \\
\text { (ten thousand of tons) }\end{array}$ & $\begin{array}{c}\text { Industry } \\
\text { (ten } \\
\text { thousand } \\
\text { of tons) }\end{array}$ & $\begin{array}{c}\text { Construction } \\
\text { industry (ten } \\
\text { thousand } \\
\text { of tons) }\end{array}$ & $\begin{array}{c}\text { Transportation } \\
\text { (ten thousand } \\
\text { of tons) }\end{array}$ & $\begin{array}{c}\text { Wholesale and } \\
\text { retail catering } \\
\text { industry (ten } \\
\text { thousand of tons) }\end{array}$ \\
\hline 2000 & 0.039 & 0.580 & 0.008 & 0.018 & 0.018 \\
2001 & 0.038 & 0.566 & 0.009 & 0.018 & 0.018 \\
2002 & 0.039 & 0.604 & 0.009 & 0.017 & 0.019 \\
2003 & 0.043 & 0.785 & 0.011 & 0.018 & 0.025 \\
2004 & 0.052 & 0.978 & 0.012 & 0.016 & 0.031 \\
2005 & 0.051 & 1.034 & 0.013 & 0.023 & 0.045 \\
2006 & 0.051 & 1.034 & 0.014 & 0.023 & 0.047 \\
2007 & 0.053 & 1.033 & 0.013 & 0.023 & 0.041 \\
2008 & 0.050 & 1.241 & 0.017 & 0.026 & 0.062 \\
2009 & 0.053 & 1.378 & 0.017 & 0.031 & 0.071 \\
\hline
\end{tabular}

Source: China energy statistic yearbook 2006 and 2010.

The carbon emissions of transport industry in the western region are relatively low, too. Although carbon emissions have a certain growth, emissions growth slowed down, only with an annual average of 2 million tons. At present, China's energy consumption per capita is 0.17 tons of standard coal and the equivalent emissions per capita are about 0.13 tons of carbon, while the western region is still less than the $1 / 15$ of the average of China. Therefore, the level of energy consumption of transport in western China is low, and the growth is slow in ten years. However, it cannot be ignored that, the western region's demand for traffic will be significantly increased with the overall economic level rise and the continuous improvement of urbanization rate, which will result in significant increase in carbon emissions.

As can be seen from Figure 1 that, the carbon emissions of wholesale and retail industry show a rapid growth trend, and the annual emission growth of this industry is about 3.2 million tons. Especially tourism and catering services play an important role in the western region, and there are still much work to be done in low carbon tourism facilities construction, low carbon tourism, the elimination of food waste, the prohibition of disposable tableware, the diversified treatment of catering garbage and rational recovery and utilization of resources [17]. Taking the use of disposable tableware as an example, about 45 billion pairs of wooden chopstick in catering industry are annually consumed, and it is equivalent to reducing forest area of 2 million square meters. It is equivalent to reducing forest area of 2 million square meters. This not only caused great damage to environmental resources, but also reduced at least 1 million tons of carbon absorption. Therefore, the potential of energy saving and emission reduction in wholesale and retail industry is very huge. 


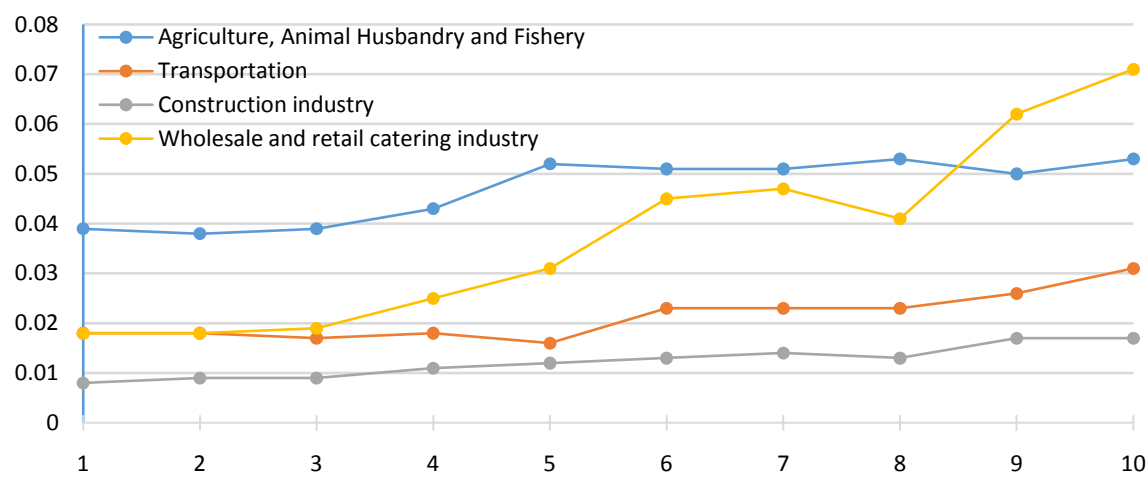

Figure 1. The carbon emission of various industrial sectors in the western region.

\subsection{Natural Resources and Environmental Endowment}

Natural resources and environment endowment are the foundation and condition of socio-economic development. Despite of backward technology level, slow economic development and low economic structure, but the western region has vast territory and rich resources. Although the northwest region is perennially arid and has less rain, it has sufficient sunshine and wind energy resources. And the southwest region is wet and has more rain, and water resources are also rich, which has a suitable ecological environment for forest and grass growing. In addition, the pluralistic national cultural characteristics, profound historical and cultural heritage and beautiful natural scenery provide unique conditions for the development of the characteristic tourism in the western region. These show that low carbon economy development in the western region has great potential and conditions.

\subsubsection{Agricultural Carbon Sink}

The western area covers 6.85 million square kilometers, and agriculture is one of the important forces of its economic development. However, unreasonable cultivation, disorder development and extensive farming have caused soil erosion and desertification for a long time, which caused serious damage to ecosystem in the western region. In addition, frequent "visits" such as drought and sandstorm have brought disastrous effect to agriculture itself, which, in turn, led to excessive reclamation and fallen into a vicious circle.

Agriculture should play the role of "carbon sink" in the context of low carbon economy, rather than the booster of "carbon source". However, modern inorganic agriculture has not only destroyed the ecological structure of land, but also become an important source of greenhouse gases such as carbon oxide and nitrogen oxides because of the large investment of machinery, chemical fertilizer, pesticides and herbicides. Therefore, actively to promote the transformation of agricultural development mode from inorganic agriculture to organic ecological agriculture has become an important work in the process of low carbon economy development. Considering the transformation of agricultural development mode, the western region should make full use of its unique resources and environmental endowment advantages. In fact, natural forest and grassland in the 
western region account for $66.2 \%$ and $66.2 \%$ of all China respectively, and are important ecological carbon sink resources [1].

Forests have more carbon sink potential compared to grassland. The study shows that forest carbon sequestration is the most powerful, with an average of 1.83 tons of carbon dioxide per cubic meter. Therefore, the western region should speed up the formation of compound forest production and operation mechanism to fully strengthen the ecological system function of forestry in carbon sink [18]. In particular, the development of ecological carbon sequestration agriculture in the western region can not only effectively protect ecological environment, but also can use carbon emissions trading mechanism (including carbon trading in developed areas and abroad) to exchange huge economic benefits. This, in turn, can fully mobilize the enthusiasm of farmers to develop ecological carbon sink agriculture, and thus form a benign interactive socio-economic development mode.

\subsubsection{Clean Energy Development}

Hydropower resources account for the largest proportion in renewable energy. The western area is the birthplace of the Yangtze River and the Yellow River, and water resources are extremely rich, accounting for $82.3 \%$ of national hydropower. Among them, exploitable hydropower resources account for $72.3 \%$ of the country. However until 2010, the proportion of hydropower resources development is less than $30 \%$ [3]. Even without considering the exploitable amount of water resources in the Yangtze River and the Yellow River, economic development capacity in the western China is also great. In particular, exploitable hydropower resources in the southwest China are extremely rich, and economic annual energy output account for more than $80 \%$ of the western region [14]. Therefore, the great potential of hydropower resources makes an optimistic prospect for energy structure transformation, energy demand growth and green environmental protection.

The northwest China has plenty of solar energy resources. Therefore, the northwest region should make full use of this natural advantage, actively build desert "sun city", and build large-scale solar and related industries. Vigorously to develop solar energy and related industries, on the one hand, can meet huge energy demand in the process of industry and urbanization in the western region, and reduce coal proportion in energy consumption. On the other hand, the promotion of solar and related industries into strategic industries or leading industries, may not only optimize industrial structure in the northwest area, but also the northwest area may transport a large amount of clean energy to the eastern area to obtain huge economic benefits, so as to drive the comprehensive development of social and economic northwest.

Wind energy resources in the western region are abundant. Wind energy has cost advantage compared with hydropower and solar energy, and has also the potential of commercialization and scale development [13]. China in "the new energy industry development plan", has planned Inner Mongolia, Gansu, Xinjiang, Hebei and Jiangsu coastal areas as seven ten million kilowatts of wind 
power base, which will bring great opportunity for the development of wind power in the western region. At present, the Gansu province's Jiuquan city has already installed 51.6 million kilowatts of wind power until 2010, and the first 10 million kilowatts of wind power base project has started to construct [19]. It will bring new opportunities and experience for energy structure improvement and clean energy development and the industrialization and commercialization of new energy technology in Gansu province and the western region.

\subsubsection{Ecological Tourism Development}

Tourism industry development has the characteristics of low energy consumption and less greenhouse gas emissions compared with other industries. Referring to the energy consumption formula of unit industrial added value, the energy consumption of tourism industry is only the one-sixth of national GDP energy consumption and the 1/11 of industrial value-added energy consumption. Therefore, tourism is known as "smokeless industry". Tourism is not only a "smokeless industry", but its development can also drive the development of other service industries such as catering industry. It plays a significant role in expanding demand, stimulating consumption and investment, and is one of the important pillar industries to promote regional economic development.

The western region has unique conditions and advantages of developing tourism economy. The tourism resources of all the provinces and cities in western China account for $40 \%$ of total country. Moreover, the western China has beautiful natural landscape, for example, 34 national nature reserve place, 40 national scenic spots, and 114 national forest parks. Among then, the Qinghai-Tibet plateau, the Xishuangbanna and the Sanjiang river basin are famous scenic landscape in the world. In addition, the humanities landscape in the western region is unique. The western region is a settlement of China's minorities. At present, China has 635 ethnic minority counties, but 596 ethnic minority counties are in the western China. Unique minority culture and ecological community has attracted a large number of tourists to visit. These have created excellent conditions for the development of ecological tourism in the western region.

More importantly, people have more and more needs for tourism with the continuous improvement of people's living standard, which brings new opportunities for the development of eco-tourism in the western region. Therefore, the western region should fully highlight the advantages of its own tourism resources in the premise of ensuring ecological sustainable development and actively create eco-tourism projects and brands with regional characteristics to achieve the win-win goal of natural environment protection and economic development.

\section{Discussion}

\subsection{Industrial Upgrading, Structure Optimization and Emission Reduction}

The basis of low carbon economy development is industrial low-carbonization. However, high energy consumption and high carbon intensity industry still 
occupies a large proportion in the existing industry in the western region. Therefore, the existing industrial layout and industrial structure must be adjusted and optimized to improve the overall development level and quality of industry.

From the perspective of industrial development, the western region is first facing the adjustment and optimization of industrial layout, as the western region has not highlighted the characteristics and advantages of regional industrial development that is different from the eastern region for a long time. In particular, a large number of low-end industries in the east will move to the western region with increasing capital intensity in the eastern region to exacerbate the contradictions of environmental deterioration in the western region. Therefore, in order to get rid of this passive development situation, it is necessary to readjust and optimize industrial layout and industrial development direction from the strategic height in order to form industrial development pattern with regional characteristics and competitive advantages. At present, the western region is facing the new opportunity of western development, and key to making full use of this new opportunity is how to build a unique regional industrial development pattern with remarkable regional characteristics. This is the first major problem to be solved in future low carbon economy development for the western region.

The adjustment and optimization of industrial structure in western region is another issue. The adjustment of industrial structure involves how to eliminate backward industry, how to transform traditional industry and how to cultivate new industries. At present, industrial development in the western region is supported by electricity, chemical industry, and steel industry, but these industries have the problem of high energy consumption, high emissions and high pollution. Therefore, the western region should quickly eliminate these "three high" industries, or make technological transformation and upgrading in to reduce energy consumption and greenhouse gas emissions from production source.

The core of the transformation of traditional industry is to promote clean production mode and develop circular economy. Only in this way, can the western region solve the problem of energy saving and emission reduction in industrial production fundamentally. At present, countries in the world are actively promoting the construction of eco-industrial parks, trying to create a complementary circular economic development mode for industrial development through industrial agglomeration and resource sharing. Practice has proved that it is a more effective way to achieve the development of cleaner production and circular economy. Currently, the western area is still in the primary stage of industrialization, which provides the conditions for future industrial agglomeration and the construction of eco-industrial parks. The western region can accelerate the transformation of traditional industries on the basis of existing industrial development to achieve the goal of industrial level promotion and industrial structure optimization through the construction of eco-industrial parks.

It is very important to cultivate strategic emerging industries for the western region. Knowledge and technology intensive industries including information, 
communication and transportation, and new green industry such new energy, new materials, energy saving and environmental protection and modern service industry, have become a strategic emerging industry and is valued by all over the world. Therefore, the western region should seize this favorable condition to cultivate and develop these strategic emerging industries with the comparative advantage of the region, so as to drive the all-round development of social economy in the western region [20].

\subsection{Ecological Environment Protection Engineering and Emission Reduction}

How to protect natural ecological environment is very important for the western region. Because the western region has a vast territory as well as rich natural and plant resources, it has extremely important position in China's natural ecological environment protection. However, the natural ecosystems of the western region, especially the northwest region, are more vulnerable. Therefore, once natural ecosystem is severely damaged, it is difficult to recover in the short term. Especially in the northwest, desertification is more and more serious due to climate change or man-made destruction. If not timely to make protection and governance, it will cause irreparable disastrous consequences.

In fact, the protection of natural ecological environment is not only to maintain the sustainable development of ecosystem, but also to make full use of its natural resources advantage to promote the development of related industries, and to form a sustainable development mode of natural, economic and social benign cycle. In the case of desertification control, sand itself is also a treasure, and not only can it be used to make construction and industrial materials, but also can it used to develop unique desert agriculture (including forest and animal husbandry). At the same time, it may also combine the development of desert agriculture and emerging ecological mode to open new agricultural tourism. These are conducive to the industrialization and urbanization development of the western region.

Many river basins are distributed in the western areas, which contain a large number of water resources and natural animal and plant resources. If the development of these river basins is combined with ecological environment protection to make comprehensive management of these basins and the rational development and utilization of rich river basin resources, it will undoubtedly greatly promote the social and economic development of the corresponding regions. Some basins have been governed in recent years with the support of the state and the active efforts of local governments, and their ecological and socioeconomic benefits have been preliminarily revealed. Therefore, if the comprehensive treatment of all the basins is practiced, their ecological and socioeconomic benefits will be considerable.

The western region can obtain huge carbon sink income through full implementing ecological environment protection project. With the establishment and improvement of carbon market and carbon trading mechanism, transaction 
scale between different regions will be larger and larger. Because the eastern region has relatively limited carbon reduction potential, it is necessary to obtain more carbon emissions through carbon trading in order to maintain rapid economic growth. On the contrary, the western region can gain huge economic benefits from large scale carbon emission cuts through the implementation of ecological environmental protection engineering, such as the full utilization of mountain area and desertification and watershed comprehensive management, to increase forest storage capacity to cut large scale carbon emissions. Therefore, if the western region can combine ecological environment protection and carbon sink industry organically, then it will create a unique ecological carbon sink economic mode. This not only helps to achieve the goal of ecological protection, but also can produce huge economic benefits.

\subsection{Reasonable Development and Utilization of Mineral Resources and Emission Reduction}

The western region contains rich mineral resources, coal, precious metals, rare earth, petroleum, natural gas and shale gas resources, which laid a solid material foundation for social and economic development in the western region. However, since these rich mineral resources have not been scientifically and rationally developed and utilized for a long term, it not only did not make social and economic prosperity in the western region, but also caused serious problems such as the destruction of natural resources and environmental pollution in some areas. Although there are many reasons for these problems, that government's macro planning and supervision is not in place is one of the important reasons.

Key to reasonable development and utilization of mineral resources is how to improve effective mining utilization and reduce damage to natural environment, which needs to improve the threshold in mining access, processing and technical standards and environmental standards. At the same time, the government need also to conduct macro guidance and management in the deep processing of mineral resources, industry chain extension and value appreciation to completely change the disadvantage of the western region as primary resources.

\subsection{The Utilization of Renewable Clean Energy Resources and Emission Reduction}

The shortage of fossil energy and its environmental pollution are more and more taken seriously, so almost all countries in the world is actively developing new energy and renewable energy. And the western region contains huge renewable clean energy resources such as hydropower, wind energy, solar energy, geothermal energy and biomass energy, which provides an excellent opportunity for energy and socio-economic development in the western region.

One of the most advantageous in the western areas is the development and utilization of hydropower resources. Because the western area is not only rich in hydropower resources, but also the costs of hydropower development and utilization are relatively low. If hydropower resources in the western area can rea- 
sonably developed and utilized combined with ecological environment protection and watershed comprehensive management, it will not only produce huge economic benefits, but also can produce huge economic benefits through power output.

The western region is not only rich in wind and solar resources, but also is vast and sparsely populated, which creates conditions for the construction of large-scale wind farm and solar electric field. At present, the main factors restricting the development of wind and solar energy are the relatively high costs of power production, which leads to their lack of competitiveness. However, the western region can use the favorable opportunity of western development to win the special policies of the country, such as building demonstration large-scale wind and solar electric fields under the financing of the state, preferential policy in investment, and encouraging the introduction of external funds and technology and cooperative development. Once the wind energy and solar energy have formed a large-scale industry, then it will not only significantly reduce power generation cost, but also will drive a large number of related industry development [21].

In short, the western region should take advantage of the favorable opportunity of western development, and promote renewable clean energy development to the height of strategic industries. These new energy industries will be the most advantageous emerging industries in the western region, and will undoubtedly play a very important role in the future social and economic development in the western region.

\subsection{Ecological Tourism Development and Emission Reduction}

The western region has the unique tourism resources, and the people's demand for tourism will be more and more exuberant with the improvement of people's living standard, which creates the conditions for the western region to give full play to its tourism resources advantages. At present, although the development of tourism in the western region is more and more valued, many areas have not still promoted tourism to the height of pillar industry. Therefore, the pull function of tourism to regional economy is limited.

At present, the biggest problem in the development of tourism in western region is the lack of scientific macro development planning and management, for example, scattered and only single-in-one scenic spots, without forming a mutual contact tourism belt and complementary scenic spots cluster, and so forth. Therefore, it is difficult to give full play to the potential and economic benefits of tourism in the western region. At the same time, some places for short-term interests make unreasonable development of tourism resources, causing that natural ecological environment has been seriously damaged. In addition, the western region failed to make tourism industry become a comprehensive industry. Therefore, although the tourism in the western region has made some development in recent years, its tourism economy has not made substantial progress.

The western region should focus on the development of comprehensive tourism 
economy based on the principle of ecological environment protection in the future. Specifically, on the one hand, the western region should develop ecological tourism with western characteristics combined with the excellent natural ecological conditions and unique minority cultural conditions, through the overall planning and coordinated development of tourism resources, and actively create a tourism culture and brand with western characteristics to attract many domestic and foreign tourists to western sightseeing and consumption. On the other hand, the development of related industries should be promoted around ecotourism to form a tourism industry and tourism economy taking eco-tourism as the core to give full play to the role of tourism industry on the economy.

\subsection{Organic Ecological Agriculture Development and Emission Reduction}

The western region is one of the most important agricultural production areas in China, playing a very important role in agricultural development in China. However, the level of agricultural modernization in the western region is relatively low compared to the eastern developed areas. In particular, agricultural production in many poor areas in western China is still mainly traditional farming methods. At the same time, the western region still retains a large number of strict regional characteristics agriculture. These all provide good conditions for the development of organic ecological agriculture, especially organic ecological agriculture with western characteristics.

Agriculture is closely related to nature in all industries. Therefore, the development of organic ecological agriculture actually constitutes an important organic part of natural ecological environment protection. In turn, good natural ecological environment can create more conditions and opportunities for the development of organic ecological agriculture. In the western region, economy still mainly depends on agriculture directly or indirectly. On the one hand, the western region has the unique conditions of developing organic ecological agriculture. Whether it is southwest, center west or northwest China has famous organic characteristic agricultural products, and some organic characteristic agricultural products are difficult to produce in other areas, or difficult to match in quality. On the other hand, the contradiction of agricultural shortage is difficult to solve completely in the short term with the continuous reduction of arable land and frequent occurrence of severe climate. More importantly, the people's demand for pollution-free and healthy organic green food will be more and more with the improvement of people's living standard. In addition, the western region may develop organic ecological agriculture with sightseeing tourism function combined with the characteristics and needs of characteristic tourism, in order to achieve industrial symbiosis and interactive development. These have created excellent conditions for the development of organic ecological agriculture in the western region.

Key to the development of organic ecological agriculture in the western region is to develop local characteristic organic ecological agriculture according to nat- 
ural agricultural resources, and make it one of the local pillar industries. Only by making it stronger, can the western region give full play to scale advantage and turn scale advantage into comprehensive competitive advantage, which requires planning, guidance and support from the macro level. On the other hand, the western region should focus on agricultural industrialization based on the development of organic ecological agriculture. Only to realize the industrialization of characteristic organic ecological agriculture, can prolong its industrial chain and realize its value to improve its comparative income. At the same time, agricultural industrialization development can also drive the development of other industries except agriculture, so that the development of characteristic organic ecological agriculture can drive the development of the whole socio-economy. This is the best way to promote regional economic development in the western region under specific natural resources and ecological environment [22].

\subsection{Urban Ecology-Oriented Development and Emission Reduction}

Urbanization is the inevitable requirement and results of the development of modern productivity, and the level of urbanization is an important aspect to measure the development of local social economy. The importance of urbanization development is that city is the regional community of population, material, capital, space and activities, so it is an important agglomeration of modern industry and service industry. The main material wealth of human society is created in the city [21] [23]. For the western region (especially northwest), because of the vulnerability of natural ecological environment in the western region (especially northwest), how to reduce the negative impact of human socio-economic activities on natural ecological environment is one of the important problems to be solved in the western region, and urbanization is an important way. Because the dispersed population can be properly concentrated in production and life through urbanization, the direct impact of decentralized human activities on natural and ecological environment in specific regions can be reduced. At the same time, the proper concentration of population to cities can promote the development and prosperity of urban industry and commerce. Therefore, to accelerate the urbanization of the western region is an inevitable requirement to promote social and economic development and the protection of natural ecological environment in the western region. However, in general, the level of urbanization in the western region is not high at this stage. Therefore, how to accelerate the urbanization development will be one of the major issues to be solved in the social and economic development of the western region.

However, because the city is an artificial environment system, the development of the city needs not only a lot of resources and energy, but also produces a lot of waste. Therefore, city has internal unsustainable from the perspective of natural ecology. In order to effectively solve the contradiction between urban ecological scarcity and the stability of urban social and economic system, it is necessary to seek the development of the city under the premise of respecting 
natural ecological law. Strategically, it is to build and develop ecological city, or to promote the ecology-oriented development of city. For the western region, the promotion of urban ecology-oriented development is not only necessary, but also has its own unique advantages. Because the western region has good natural resources and ecological environmental conditions, scientific and reasonable development and utilization through the way of ecological city construction and development, not only will not destroy the existing natural ecological environment, but also be conducive to gaining maximum ecological and socio-economic benefits. At present, Chengdu has clearly put forward that its future development goal is to build a world garden city, and other western cities also began to pay attention to the construction and development of ecological city. However, overall, it is still only in the stage of conceptualization and experimental development, and thereby far from the requirements of eco-city development. However, it is foreseeable that accelerated urban ecological development will undoubtedly inject new vitality and motivation into the future socio-economic development of the western region [24].

\section{Concluding Remarks}

The western region, as an important ecological barrier, plays an important role in the development of low carbon economy. However, extensive economic growth mode in the western region is common, and the economic growth structure of high energy consumption, high emissions and high pollution has yet to be improved. Especially, natural ecosystem in the western region is relatively fragile. How to promote the rapid development of social economy under the premise of comprehensive and effective protection of ecological environment is a significant problem to be solved in the western region for a long period of time. This requires the western region to promote the development of low carbon economy, which is the most powerful guarantee for the harmonious development of natural, economic and social harmony.

In fact, from the reality conditions of the western region, because of the sparsely populated in the western region, economy is not developed. Therefore, the basis of natural ecological environment in the western region is relatively good, which creates good conditions for future low carbon economy development. The key of the problem is how to establish social and economic development strategy that is suitable for the specific natural conditions of the western region, how to achieve the harmony of ecological environment protection and social economic development, how to accelerate the transformation of economy from extensive development to intensive mode, and how to choose leading industry and pillar industry to accelerate social and economic development. As long as development ideas and planning are correct, strategic positioning is accurate, development mode choice is appropriate, and industrial structure is reasonable, then the western region can achieve the great goals and tasks of natural, economic and social harmonious development.

In the present stage of development, the western region has not only great po- 
tential in technology progress, industrial upgrading and energy saving and emission reduction, but also has good natural resources and environmental conditions in the development of agricultural carbon sequestration, eco-tourism development and clean energy development. Therefore, the western region can realize the dual goals and tasks of social economic development and environmental protection through many ways. At present, the focus of the work should be to actively promote industrial upgrading and structural optimization, comprehensively to implement natural ecological protection engineering, rationally to develop and use mineral resources, fully to utilize renewable clean energy resources, vigorously to promote the development of eco-tourism, to give priority to organic ecological agriculture, and to accelerate urbanization and urban ecological development.

\section{Acknowledgements}

This work was supported by the National Social Science Foundation of China under Grant 10XJY004. The author appreciates generous support from the funds. In particular, I want to thank to Shanshan Zhao, because she has done a lot of work for this article. In addition, the constructive comments of anonymous reviewers are thankfully acknowledged.

\section{References}

[1] Hai, X.W. (2010) The Development of Carbon Sink Potential and Agricultural Carbon Sink Industry Development in Western China. Frontier, 15, 105-108.

[2] Zhan, C.L., An, J.W., Wen, J.Y. and Ming, L. (2010) Regional Carbon Emission Research in China. Journal of the Earth, 31, 727-732.

[3] Shao, H.C. and Sheng, N.C. (2012) Low Carbon Economy Constraint and the Development of Resource-Based Industry in the Western China. Commercial Research, 5, 140-145.

[4] Qi, L., Shu, D., Ru, Y.W. and Qiang, Y.C. (2011) The North-South Investment Share, Consumption Share and Pollution Analysis under Environmental Control. World Economy, 8, 44-65.

[5] Tao, T.J. and Bao, H.Z. (2011) Convergence of Total Factor Productivity in China under Low Carbon Economy. Economic Issues, 12, 31-35.

[6] Grossman, G.M. and Krueger, A.B. (1991) Environmental Impacts of a North American Free Trade Agreement. National Bureau of Economic Research, Cambridge.

[7] Wei, F.Z. and Chang, F.Z. (2011) China's Carbon Emissions Trajectory Presents a Kuznets Inverse U Shape? Based on the Analysis of Relationship between Regional Economic Development and Carbon Emissions. Economic Management, 6, 14-23.

[8] Guang, Y.X. and De, Y.S. (2010) Empirical Study of Environmental Kuznets Curve of Carbon Emissions in China Based on Provincial Panel Data. China Industrial Economy, 5, 37-47.

[9] Bang, Y.S. and Fang, L.S. (2011) The Impact Factors of Carbon Emissions in China's East Midwest with Panel Data. Regional Research and Development, 30, 19-24.

[10] Mei, Z. (2010) On the Feasibility of Low Carbon Economy Development in the Underdeveloped Areas of the Western China. Journal of Theory Survey, 9, 83-87. 
[11] Yu, J.S., Yu, Z.Z. and Peng, L. (2011) Evaluation of Rational Use for Regional Land under Low Carbon Background. Regional Research and Development, 30, 93-117.

[12] Bo, L. (2011) Necessity and Countermeasures of Low Carbon Economy Development in Western China. Social Sciences in Ningxia, 6, 67-69.

[13] Institute of Climate Change and Low Carbon Economy of Renmin University of China (2010) Low Carbon Economy: China Action Told Copenhagen. Petroleum Industry Press, Beijing.

[14] Wei, D.L. (2010) The Path of China's Low Carbon Economy Development Framework and Scientific Base: Reducing Carbon Emissions of Unit GDP by 2020 40\%45\%. Commercial Press, Beijing.

[15] Dan, G. (2011) Research on the Countermeasures of Low Carbon Transformation of County Economy in the Western China. Journal of Inner Mongolia University of Finance and Economics, 6, 105-108.

[16] Xue, M.H. and Huan, H.L. (2009) The Dynamic Comparison of Ecological Consumption and Economic Development in China: A Consideration of Low Carbon Economy in Western China. Journal of Lanzhou University, 37, 118-126.

[17] Xun, X. and Guo, Z.Z. (2011) The Transformation of Catering Industry in Low Carbon City Construction. Social Scientist, 4, 71-75.

[18] Shu, Y.L. (2011) Discussion on Low Carbon Economy Development and Ecological Civilization Construction in Western China. Doctor Thesis, Kunming University of Technology, Kunming.

[19] Cheng, C., Jian, J.Z. and Yong, N.C. (2010) Investigation on Low Carbon Economy Development in Western Underdeveloped Areas: A Case Study of Jiuquan in Gansu Province. Western Finance, 4, 50-51.

[20] Xiang, S.D. (2013) Low Carbon Economy Development: China's Pattern and Policy Selection. Energy Policy, 63, 1013-1020. https://doi.org/10.1016/j.enpol.2013.08.089

[21] Xiang, S.D. (2015) Essence, Feature and Role of Low Carbon Economy. Environment, Development and Sustainability, 17, 123-136. https://doi.org/10.1007/s10668-014-9542-9

[22] Xiang, S.D. (2009) Strategic Thinking on the Problem of Agriculture, Countryside and Farmers. Scientific Decision-Making, 10, 1-15.

[23] Wen, H.X. and Wei, D. (1996) Urban Economics. Tsinghua University Press, Beijing.

[24] Xiang, S.D., Sha, S.L. and Jing, W. (2012) Ecological Strategy of City Sustainable Development. APCBEES Procedia, 5, 410-415. 
Submit or recommend next manuscript to SCIRP and we will provide best service for you:

Accepting pre-submission inquiries through Email, Facebook, LinkedIn, Twitter, etc. A wide selection of journals (inclusive of 9 subjects, more than 200 journals)

Providing 24-hour high-quality service

User-friendly online submission system

Fair and swift peer-review system

Efficient typesetting and proofreading procedure

Display of the result of downloads and visits, as well as the number of cited articles Maximum dissemination of your research work

Submit your manuscript at: http://papersubmission.scirp.org/

Or contact tel@scirp.org 